\title{
A Statistical Method for Determining the Best Zinc Pregnant Solution for the Extraction by D2EHPA
}

\author{
Hossein Kamran Haghighi ${ }^{1}$, Davood Moradkhani ${ }^{2}$, Mohammad Mehdi Salarirad ${ }^{1}$ \\ ${ }^{1}$ Department of Mining and Metallurgical Engineering, Amirkabir University of Technology, Tehran, Iran \\ ${ }^{2}$ Faculty of Engineering, University of Zanjan, Zanjan, Iran \\ Email: h.kamran.h@aut.ac.ir,dmoradkhani@gmail.com, salarim@yahoo.com
}

Received May 14, 2013; revised July 17, 2013; accepted September 2, 2013

Copyright (C) 2013 Hossein Kamran Haghighi et al. This is an open access article distributed under the Creative Commons Attribution License, which permits unrestricted use, distribution, and reproduction in any medium, provided the original work is properly cited.

\begin{abstract}
The application of D2EHPA in zinc solvent extraction has extensive background. To utilize more effectively, response surface methodology was used to optimize the concentration condition of zinc pregnant solution (ZPL) extracted by D2EHPA. In the current research, zinc, iron and manganese extraction along with separation factor of zinc-iron (Sf (Zn$\mathrm{Fe})$ ) and zinc-manganese (Sf (Zn-Mn)) were considered as the response values. The optimal ZPL conditions extracted with 30\% D2EHPA as the extraction solvent were as follows: Zn 21.96 g/L, Fe 382.57 ppm, Mn 1 g/L, Sf (Zn-Fe) 8.26 and Sf (Zn-Mn) 1529.82. In addition, it was found that the iron and manganese concentration were the most effective factors affecting the zinc and manganese extraction, respectively.
\end{abstract}

Keywords: D2EHPA; Response Surface Methodology; Pregnant Solution; Optimization

\section{Introduction}

The extraction of zinc sulfate with di-2-ethylhexyl phosphoric acid (D2EHPA) is a well-known route in zinc purification industry. According to the literatures, extraction of zinc increases from $10 \%$ to ca. $99 \%$ with increasing $\mathrm{pH}$ from 0.5 to 2.5 and increasing D2EHPA concentration from $5 \%$ to $40 \%(\mathrm{w} / \mathrm{w})$ [1]. It is obvious that enhancement of extractant makes distribution coefficient increase; however, it is noteworthy that the high cost of the organic extractant limits the usage of D2EHPA to less than $30 \%(\mathrm{v} / \mathrm{v}$ or $\mathrm{w} / \mathrm{w})$ [2]; therefore, the best composition of D2EHPA in industrial zinc solvent extraction is $30 \%(\mathrm{v} / \mathrm{v})$ dissolved in kerosene.

Mehdi Abad lead and Zinc mine located in Yazd, Iran with the fixed capacity of $200 \mathrm{M}$ tons of sulfur and oxide ore is one of the greatest lead and zinc mines in the world. The investigations reveal that manganese and iron are the main and major impurities of Mehdi Abad ore, which consequently come to leach solution and associate with zinc ion. Therefore, evaluating the optimized concentration of impurities for solvent extraction process plays the significant role in the leaching and pre-concentration steps. These impurities have undesirable effect on the process. For instance, $\mathrm{Mn}^{2+}$ ions, oxidized anodically to $\mathrm{MnO}_{4}^{-}$ions, depolarize the $\mathrm{H}^{+}$ions discharge and thus reduce the current efficiency for zinc deposition [3-7].
Furthermore the iron constitutes a severe impurity in zinc solution and must be removed before electrolysis [8]. Implementing iron (III) solvent extraction into the zinc roast-leach-electrowin flowsheet as a means of iron rejection has been under consideration for at least two decades [9].

Response surface methodology is used to reduce the number of assays necessary to optimize the process and to collect results more precise than those obtainable by traditional full factorial designs [10,11]. Accordingly, RSM has been increasingly employed to optimize solvent extraction process. However, there is little information that shows which concentration of ZPL can be optimally extracted by D2EHPA. Therefore, the optimization condition of ZPL in detail which is extracted optimally by $30 \%(\mathrm{v} / \mathrm{v})$ D2EHPA is the aim of this report. In the present research, the best concentrations of iron, manganese and zinc concentration, which are significant factor in Mehdi Abad ore, were found. Furthermore, the interactions effects between ions and the most effective factors on extractions were investigated.

\section{Experiment}

\subsection{Reagents}

Analytical grade inorganic reagents used in the experi- 
ments have been illustrated in Table 1. The synthetic solutions were prepared with the chemicals at the target concentrations and are presented in Table 2. The extractant, D2EHPA, was provided from BDH in England. It was dissolved in the industrial kerosene from Tehran Refinery Company, Iran as the diluent. The metal ion concentrations in the solutions were analyzed by PerkinElmer AA300 model atomic absorption spectro-photometer.

\subsection{Procedure of Extraction}

The extraction experiments were carried out in mechani- call agitated and thermostatic beakers. In each experiment, $50 \mathrm{~mL}$ of the solution containing various zinc, iron and manganese concentrations (see Table 3) and $50 \mathrm{~mL}$ of the extractant were agitated by a magnetic stirrer at a constant rate. The $\mathrm{pH}$ of the solution was adjusted to 2.5 by sulfuric acid and hydrogen hydroxide. After agitating the beakers for $10 \mathrm{~min}$ at equilibrium state, the organic phase was separated from the aqueous phase in a separator funnel. After separation, the concentrations of ions in the aqueous phase were analyzed by Perkin-Elmer AA300 model atomic absorption spectrophotometer. Concentration of metal ions calculation in the organic

Table 1. Inorganic reagents used in the experiments.

\begin{tabular}{cccc}
\hline Solution/Application & Component & Supplier & Prepared Concentration \\
\hline Aq. Feed & $\mathrm{MgSO}_{4} \cdot \mathrm{H}_{2} \mathrm{O}$ & Fisher & See Table 2 \\
Aq. Feed & $\mathrm{FeSO}_{4} \cdot 7 \mathrm{H}_{2} \mathrm{O}$ & Merck & See Table 2 \\
Aq. Feed & $\mathrm{ZnSO}_{4} \cdot \mathrm{H}_{2} \mathrm{O}$ & Merck & See Table 2 \\
Aq. Feed & $\mathrm{H}_{2} \mathrm{O}_{2}$ & Mojallali & $3 \mathrm{cc}$ per liter \\
pH adjusting & $\mathrm{H}_{2} \mathrm{SO}_{4}$ & Mojallali & $98 \%$ \\
pH adjusting & $\mathrm{NaOH}$ & Mojallali & $36 \%$ \\
\hline
\end{tabular}

Table 2. The coded values and corresponding actual values of the optimization parameters.

\begin{tabular}{cccccc}
\hline Factor & Name & Units & Type & Low Actual & High Actual \\
\hline A & Zn & g/L & Numeric & 15 & 60 \\
B & Fe & ppm & Numeric & 10 & 1000 \\
C & Mn & g/L & Numeric & 1 & 5 \\
\hline
\end{tabular}

Table 3. The coded, experimental and predicted values for RSM design using D2EHPA as solvent.

\begin{tabular}{|c|c|c|c|c|c|c|c|c|}
\hline & Factor 1 & Factor 2 & Factor 3 & Resp. 1 & Resp. 2 & Resp. 3 & Resp. 4 & Resp. 5 \\
\hline Run & A: Zn g/L & B: Fe ppm & C: Mn g/L & $\% \mathrm{E} \mathrm{Zn}$ & $\% \mathrm{E} \mathrm{Fe}$ & $\% \mathrm{E} \mathrm{Mn}$ & Sf (Zn-Fe) & Sf (Zn-Mn) \\
\hline 1 & 38.8 & 150.25 & 2.20225 & 100 & 100 & 31.88784 & 0.258231 & 82874.33 \\
\hline 2 & 13.1625 & 10.83 & 0.9145 & 100 & 100 & 78.13013 & 1.215394 & 3684.115 \\
\hline 3 & 15.36 & 754.3 & 1.055 & 99.86784 & 100 & 64.52133 & 0.001002 & 415.5133 \\
\hline 4 & 15 & 10 & 5 & 99.8432 & 98.6 & 61.98 & 9.041147 & 390.6007 \\
\hline 5 & 23.765 & 155.4 & 0.959 & 99.91601 & 99.10553 & 38.18561 & 10.73688 & 1925.76 \\
\hline 6 & 13.11 & 11.17 & 4.354 & 87.12433 & 99.99991 & 99.45361 & $6.06 \mathrm{E}-06$ & 0.037175 \\
\hline 7 & 40.65 & 45 & 2.946 & 92.61993 & 99.99978 & 66.05567 & $2.79 \mathrm{E}-05$ & 6.449126 \\
\hline 8 & 15.81 & 494.3 & 3.276 & 93.52309 & 99.98988 & 99.42643 & 0.001461 & 0.083297 \\
\hline 9 & 44.65 & 561.9 & 0.6347 & 63.91937 & 99.61559 & 9.878683 & 0.006836 & 16.1617 \\
\hline 11 & 24.07 & 750.1 & 4.921 & 81.79477 & 99.94267 & 17.57773 & 0.002577 & 21.06741 \\
\hline 12 & 28.1 & 7.29 & 1.9926 & 87.16014 & 99.98601 & 75.27351 & 0.00095 & 2.229862 \\
\hline 13 & 32.82 & 764.2 & 2.565 & 80.34735 & 99.91364 & 10.72125 & 0.003534 & 34.04499 \\
\hline 14 & 15.02 & 733.8 & 0.921 & 99.9674 & 99.91823 & 55.23344 & 2.509152 & 2485.134 \\
\hline 15 & 56.2 & 14.58 & 0.9963 & 93.58007 & 99.993 & 50.54702 & 0.00102 & 14.261 \\
\hline 16 & 28.175 & 394.1 & 2.537 & 83.9929 & 99.92641 & 8.671659 & 0.003864 & 55.26286 \\
\hline 17 & 13.1625 & 10.83 & 0.9145 & 100 & 100 & 100 & ignored & ignored \\
\hline
\end{tabular}


phase was carried out according to the concentrations of ions in the aqueous phase.

\subsection{Experimental Design of RSM}

To determine the optimal combination of extraction variables for the extraction ions, response surface method (RSM) was used. Table 2 shows the coded parameters and their levels, and Table 3 illustrates the coded, experimental and predicted values. As seen in Table 3, three factors (i.e. concentrations of three ions) as the inputted data were used to model the extraction. The values for the extraction percent of zinc, iron, manganese (\%E $\mathrm{Zn}, \% \mathrm{E} \mathrm{Fe}$ and $\% \mathrm{E} \mathrm{Mn),} \mathrm{separation} \mathrm{factor} \mathrm{of} \mathrm{zinc-iron}$ (Sf (Zn-Fe)) and zinc-manganese (Sf (Zn-Mn)) in each trial were average of duplicates. Based on the experimental data, regression analysis was done and fitted into the quadratic model as shown in Equation (1).

$$
\begin{aligned}
Y= & A_{0}+\sum_{i=1}^{k} A_{i} X_{i}+\sum_{i=1}^{k} A_{i i} X_{i}^{2} \\
& +\sum_{i=1}^{k=1} \sum_{j=i+1}^{k} A i_{j} X_{i} X_{j}+e_{i}
\end{aligned}
$$

where $Y$ represents the response, $X_{i}$ and $X_{j}$ are variables, $k$ is the number of independent variables (factors), $A_{0}$ is assigned as the constant coefficient, $A_{i i}$ and $A_{i j}$ are interaction coefficients of linear, quadratic and the secondorder terms, respectively, and ei stands for the error. Design-Expert 7.0.1.0 (Trial version, Stat-Ease Inc., Minneanopolis, MN, USA) was used for the experimental design and regression analysis of the experimental data. The Student's t-test and Fischer's F-test were used to check the statistical significance of the regression coefficient, and determine the second-order model equation, respectively. The lack of fit, the coefficient of determination $\left(R^{2}\right)$ and the F-test value obtained from the analysis of variance (ANOVA) were applied to evaluate the adequacy of the model.

\section{Result and Discussion}

If all the aforementioned variables are assumed to be measurable, the response surface will be expressed as Equation (2):

$$
Y=f\left(X_{1}, X_{2}, X_{3}, \cdots, X_{i}\right)
$$

where $Y$ is candidate of responses and the $X_{i}$ variables are called factors. To model using RSM, a total of 18 experimental runs are required. The results inserted to Design Expert software were used to fit a model to these results. The equations of models in terms of coded factors are obtained as Equations (3) to (5) for \%E $\mathrm{Zn}, \% \mathrm{E}$ $\mathrm{Mn}, \mathrm{Sf}(\mathrm{Zn}-\mathrm{Fe})$ and Sf (Zn-Mn), respectively:

For \%E Zn:

$$
\begin{aligned}
\% \mathrm{E} \mathrm{Zn=} & +81.43-12.09 X_{1}-11.65 X_{2}+6.14 X_{3} \\
& -8.97 X_{1} X_{2}+12.83 X_{1} X_{3}-3.66 X_{2} X_{3}
\end{aligned}
$$

The equation of model for iron extraction is not significant because p-value of model is less than 0.05 . This is due to high extraction percent of iron (III) in any $\mathrm{pH}$ ranges, which reaches above $99 \%$.

For \%E Mn:

$$
\begin{aligned}
\% \mathrm{E} \mathrm{Mn}= & -19.31-27.09 X_{1}-22.78 X_{2}-58.09 X_{3} \\
& -74.38 X_{1} X_{2}-78.88 X_{1} X_{3}+29.75 X_{2} X_{3} \\
& +94.90 X_{1}^{2}+60.53 X_{2}^{2}-43.60 X_{3}^{2}
\end{aligned}
$$

Selective extraction of A ion from $B$ ion can be expressed by $\mathrm{Sf}(\mathrm{A}-\mathrm{B})=\mathrm{D}_{\mathrm{A}} / \mathrm{D}_{\mathrm{B}}$,

where $D_{\mathrm{A}}=[\mathrm{A}]_{\text {organic }} /[\mathrm{B}]_{\text {aqueous }}$

and $D_{B}=[B]_{\text {organic }} /[A]_{\text {aqueous }}$. The equation of model for $\mathrm{Sf}(\mathrm{Zn}-\mathrm{Fe})$ is not presented in this study because it is not significant due to p-value less than 0.05. Nevertheless, Sf (Zn-Mn) has been modeled using RSM as Equationn (5).

$$
\begin{aligned}
\operatorname{Sf}(\mathrm{Zn}-\mathrm{Mn})= & -560.69-1419.98 X_{1} \\
& -387.08 X_{2}-1014.53 X_{3}
\end{aligned}
$$

The result of analysis of variance (ANOVA) is illustrated in Table 4-6.

The results of this table reveal that the prediction models of the zinc and manganese extraction percent and separation factor of zinc-manganese are significant since the p-value is less than 0.05 .

The result of Table 4 indicated that the effect of ions concentration and their interactions on the zinc extraction are not significant. As observed in this table, iron concentration has the highest effect on zinc extraction. The reason for this effect is probably because of selective extraction of iron (III) ions (i.e., among other species) by D2EHPA. Table 5 illustrates the results of Mn extraction. The effect of all factors (variables) and their interactions except zinc concentration are significant on Mn extraction. As Table 5, manganese concentration has the highest effect on manganese extraction. In addition, Table 6 displays that the results of $\mathrm{Sf}(\mathrm{Zn}-\mathrm{Mn})$, the zinc and manganese concentration are only significant factors. The high value of correlation coefficient $\left(R^{2}\right)$ indicates that the model has been fitted very well. If this is a response surface design which is intended to be used for modeling the design space, then the R-squared values should be rather high (perhaps above 0.60) (Design Expert 7 Help). $R^{2}$ was found to be 0.904 for $\% \mathrm{E} \mathrm{Zn,} 0.991$ for $\% \mathrm{E} \mathrm{Mn}$ and 0.627 for $\mathrm{Sf}(\mathrm{Zn}-\mathrm{Mn})$, as shown in Figures 1 to 3, which are acceptable statistically.

\subsection{D Response Surface Plots}

The 3D response surface plots simulated by Design-Expert software are graphical representations in order to understand the interaction effects of variables and the 
Table 4. Analysis of variance (ANOVA) of developed models for zinc extraction.

\begin{tabular}{|c|c|c|c|c|c|c|}
\hline Source & Sum of Squares & df & Mean Square & F-Value & p-value Prob > F & comment \\
\hline Model & 1841.69 & 6 & 306.95 & 11.04 & 0.0029 & significant \\
\hline$A-Z n$ & 79.98 & 1 & 79.98 & 2.88 & 0.1336 & \\
\hline $\mathrm{B}-\mathrm{Fe}$ & 151.85 & 1 & 151.85 & 5.46 & 0.052 & \\
\hline C-Mn & 40.43 & 1 & 40.43 & 1.45 & 0.2669 & \\
\hline $\mathrm{AB}$ & 38.9 & 1 & 38.9 & 1.4 & 0.2754 & \\
\hline $\mathrm{AC}$ & 83.32 & 1 & 83.32 & 3 & 0.127 & \\
\hline $\mathrm{BC}$ & 27.87 & 1 & 27.87 & 1 & 0.35 & \\
\hline Residual & 194.54 & 7 & 27.79 & & & \\
\hline Lack of Fit & 194.54 & 6 & 32.42 & & & \\
\hline Pure Error & 0 & 1 & 0 & & & \\
\hline
\end{tabular}

Table 5. Analysis of variance (ANOVA) of developed models for manganese extraction.

\begin{tabular}{|c|c|c|c|c|c|c|}
\hline Source & Sum of Squares & $\mathrm{df}$ & Mean Square & F-Value & p-value Prob > F & \\
\hline Model & 14489.83 & 9 & 1609.981 & 50.42903 & 0.0009 & significan \\
\hline A-Zn & 127.3896 & 1 & 127.3896 & 3.990193 & 0.1164 & \\
\hline $\mathrm{B}-\mathrm{Fe}$ & 357.9424 & 1 & 357.9424 & 11.21174 & 0.0286 & significan \\
\hline C-Mn & 1330.366 & 1 & 1330.366 & 41.67074 & 0.0030 & significan \\
\hline $\mathrm{AB}$ & 2234.237 & 1 & 2234.237 & 69.98246 & 0.0011 & significan \\
\hline $\mathrm{AC}$ & 1478.275 & 1 & 1478.275 & 46.30365 & 0.0024 & significan \\
\hline $\mathrm{BC}$ & 1176.359 & 1 & 1176.359 & 36.84678 & 0.0037 & significan \\
\hline $\mathrm{A}^{\wedge} 2$ & 2206.262 & 1 & 2206.262 & 69.1062 & 0.0011 & significan \\
\hline $\mathrm{B}^{\wedge} 2$ & 1087.321 & 1 & 1087.321 & 34.05789 & 0.0043 & significan \\
\hline $\mathrm{C}^{\wedge} 2$ & 2547.387 & 1 & 2547.387 & 79.79115 & 0.0009 & significan \\
\hline Residual & 127.7027 & 4 & 31.92568 & & & \\
\hline Lack of Fit & 127.7027 & 3 & 42.56757 & & & \\
\hline Pure Error & 0 & 1 & 0 & & & \\
\hline Cor Total & 14617.53 & 13 & & & & \\
\hline
\end{tabular}

Table 6. Analysis of variance (ANOVA) of developed models for separation factor of zinc and manganese.

\begin{tabular}{|c|c|c|c|c|c|c|}
\hline Source & Sum of Squares & df & Mean Square & F-Value & p-value Prob > F & \\
\hline Model & $1.12 \mathrm{E}+07$ & 3 & $3.75 E+06$ & 5.6 & 0.0162 & significant \\
\hline A-Zn & $6.28 \mathrm{E}+06$ & 1 & $6.28 E+06$ & 9.39 & 0.012 & significant \\
\hline $\mathrm{B}-\mathrm{Fe}$ & $7.73 E+05$ & 1 & $7.73 E+05$ & 1.15 & 0.3078 & \\
\hline C-Mn & $7.40 \mathrm{E}+06$ & 1 & $7.40 \mathrm{E}+06$ & 11.06 & 0.0077 & significant \\
\hline Residual & $6.69 E+06$ & 10 & $6.69 \mathrm{E}+05$ & & & \\
\hline Lack of Fit & $6.69 E+06$ & 9 & $7.44 \mathrm{E}+05$ & & & \\
\hline Pure Error & 0 & 1 & 0 & & & \\
\hline Cor Total & $1.79 E+07$ & 13 & & & & \\
\hline
\end{tabular}

relationship between the variables and responses. Three dimensional (3D) plots for the aforementioned responses were molded based on the model equations for zinc and manganese extraction and separation factor of zinc- manganese as Equations (3) to (5). These plots are shown in Figures 4 to 6. In these figures, two variables versus responses at the center level of third variable have constructed the plots. 


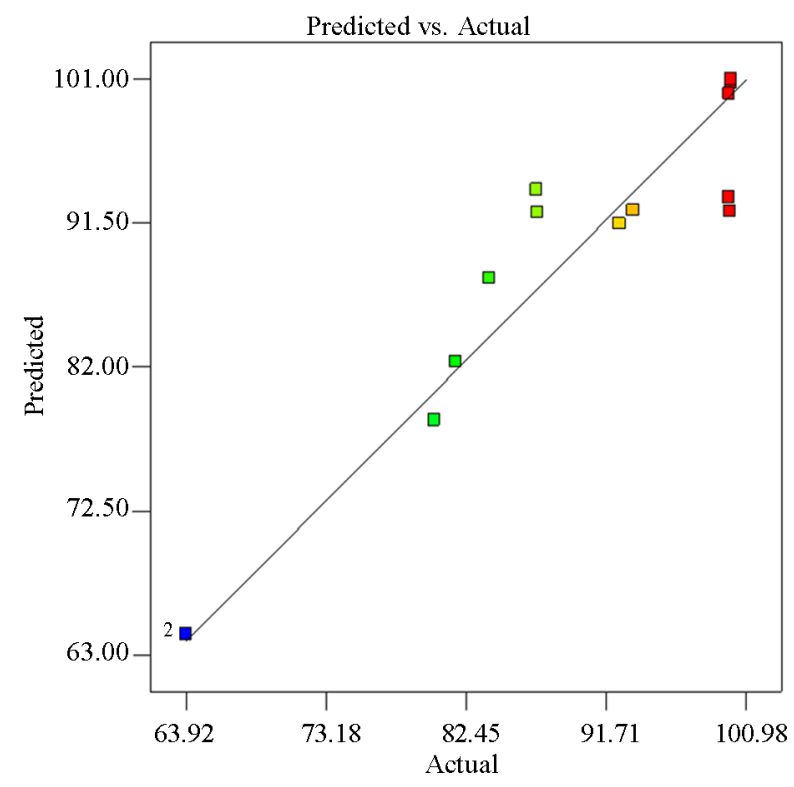

Figure 1. Relationship between predicted and actual (observed) values for zinc extraction.

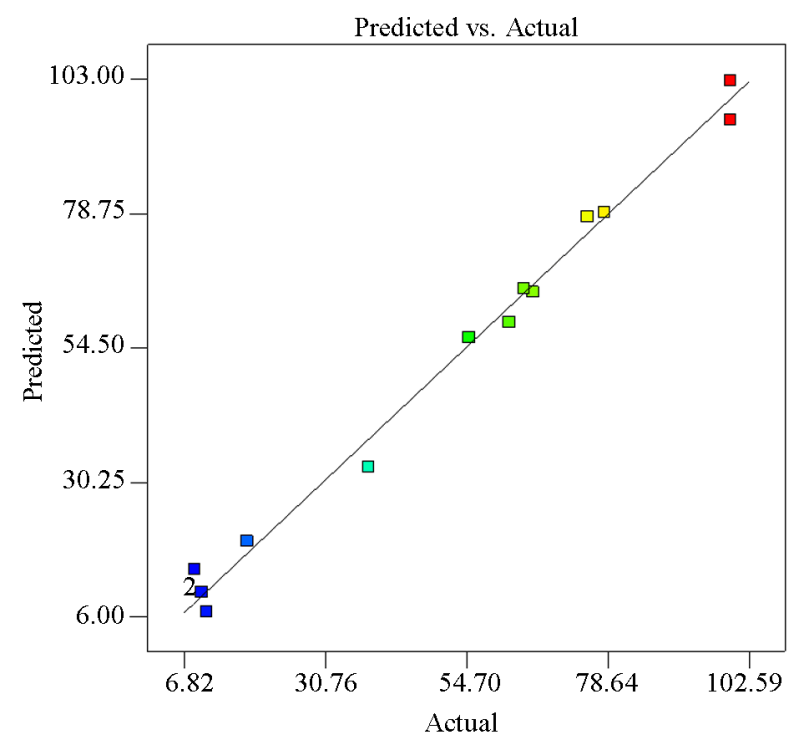

Figure 2. Relationship between predicted and actual (observed) values for manganese extraction

Figure 4(a) shows the effect of manganese and iron concentration on zinc extraction at $40^{\circ} \mathrm{C}$ and $\mathrm{pH}$ of 2.5 . It expresses that increasing iron concentration in the aqueous feed decreases zinc extraction and enhancement of manganese concentration increases zinc ions extraction. Figure 4(b) demonstrates that at high levels of zinc and manganese concentrations, the zinc extraction decreases. Furthermore, in Figure 4(c), enhancement of zinc and iron ions in the aqueous phase reduces zinc extraction. It is noteworthy that high concentration of ions in aqueous phase diminishes the capability of D2EHPA, which is related to specific capacity of extractant; moreover, Fig-

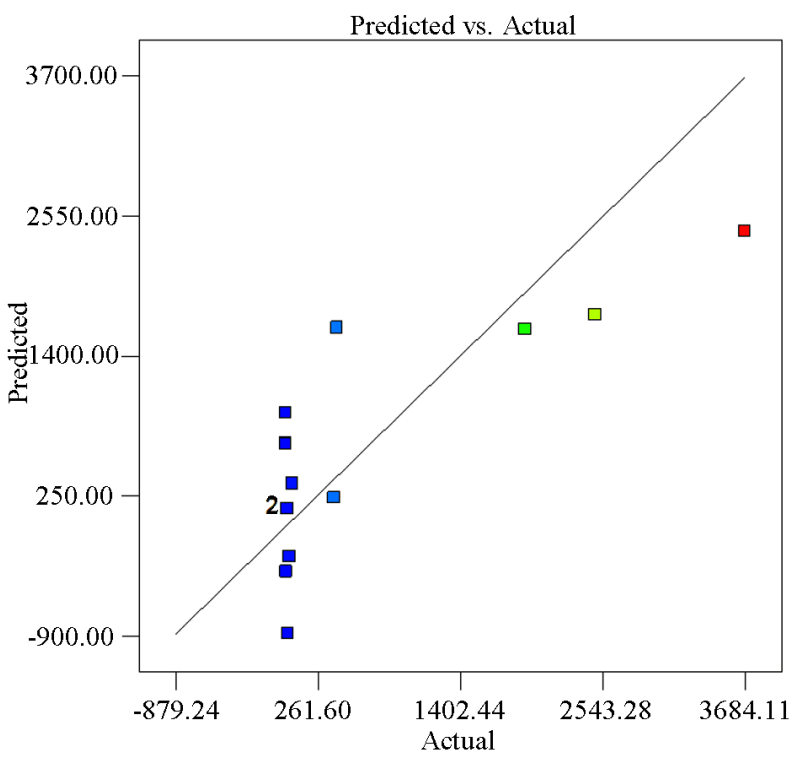

Figure 3. Relationship between predicted and actual (observed) values for separation factor of zinc and manganese.

ures $\mathbf{4 ( b )}$ and (c) justify this note.

Figure 5(a) shows considerable effect of iron concentration and invariable effect of manganese concentration on the manganese extraction. Figure 5(b) illustrates that enhancement of manganese ions in the aqueous phase increases its extraction. In addition, this figure shows that zinc ions have approximately invariable effect on manganese extraction. In Figure 5(c), the effect of zinc and iron concentrations on manganese extraction is relative. As seen in this figure, the lowest manganese extraction has occurred at the middle levels of zinc and iron concentrations. Finally, all plots of Figure 6 shows that higher amount of ions in the aqueous phase decreases separation factor of zinc-manganese.

\subsection{Optimization by RSM}

The aim of optimization is to have ZPL with the lowest impurities. Therefore, the highest zinc extraction, the lowest iron and manganese extraction and the highest values of separation factors were considered for optimizing by RSM. This optimization was carried out by DX7 software and the results of the process optimization with respect to the aforementioned aim were obtained as illustrated in Table 7. As seen in this table, the zinc, iron and manganese extraction percent at $\mathrm{pH}$ of 2 and temperature of $40^{\circ} \mathrm{C}$ reached $93.72 \%, 99.20 \%$ and $11.18 \%$, respectively. At this condition, it was found that $\mathrm{Zn}$ $21.22 \mathrm{~g} / \mathrm{L}$, Fe $376.08 \mathrm{ppm}$ and $\mathrm{Mn} 1.00 \mathrm{~g} / \mathrm{L}$ are extracted by $30 \%(\mathrm{v} / \mathrm{v})$ D2EHPA dissolved in kerosene.

This result reveals that to extract more effectively by 30\% D2EHPA, the best ZPL should be as the optimum condition of ions concentration. The desirability of this 

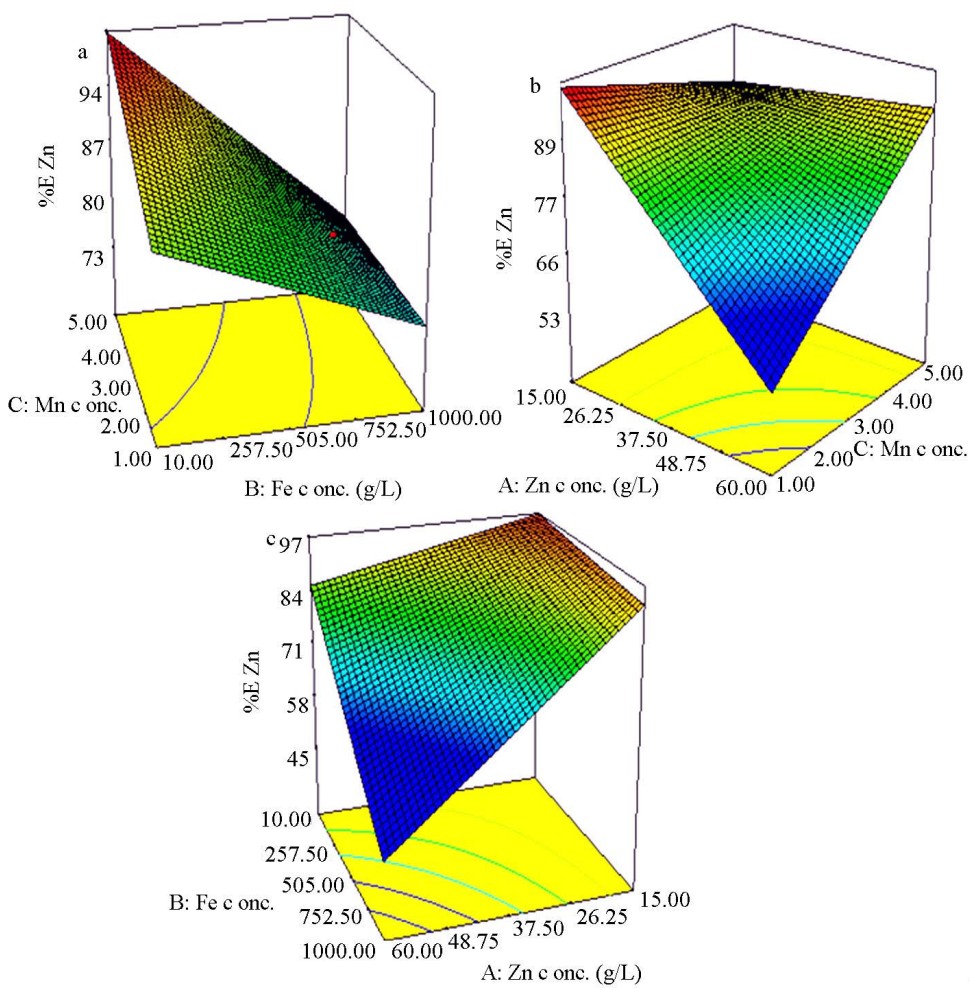

Figure 4. 3D response surface plots showing effect of two variables (factors) on zinc extraction at the center level of other variable. (a) $\mathrm{Mn}$ and Fe concentration (g/L and ppm, respectively). (b) $\mathrm{Zn}$ and $\mathrm{Mn}$ concentration (g/L). (c) $\mathrm{Zn}$ and Fe concentration (g/L and ppm, respectively).
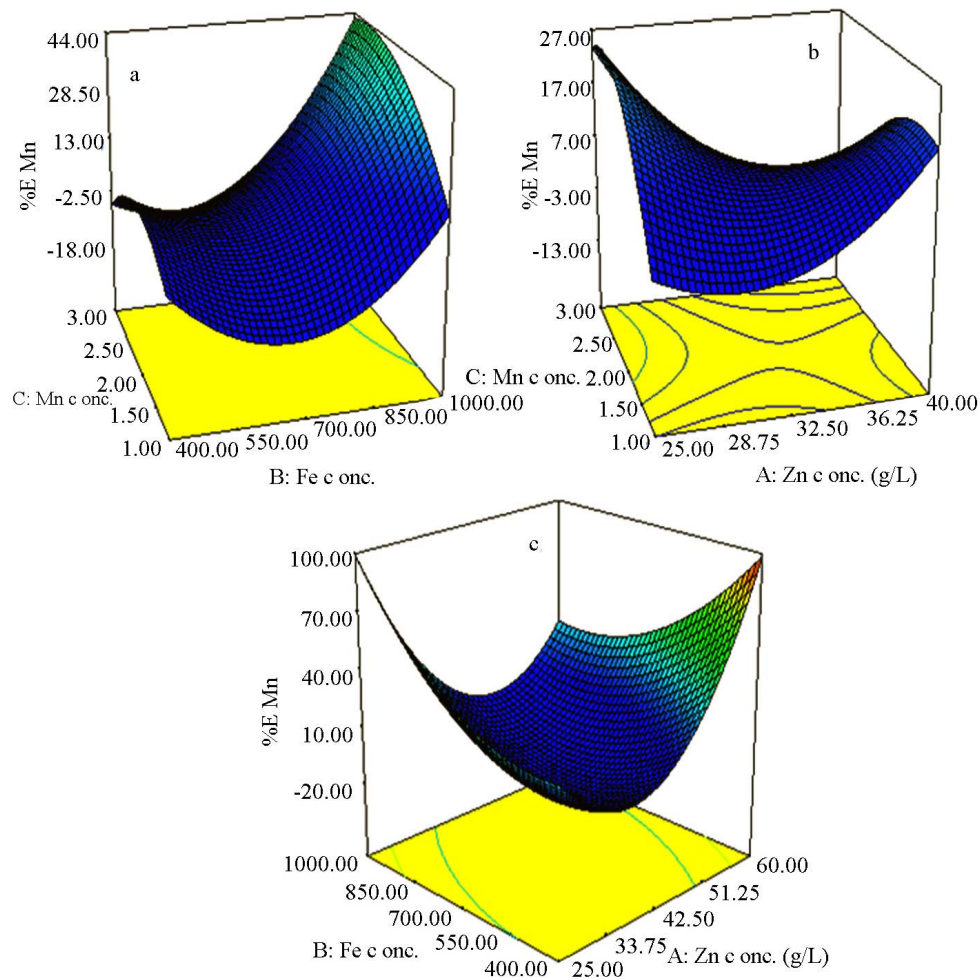

Figure 5. 3D response surface plots showing effect of two variables (factors) on manganese extraction at the center level of other variable. (a) Mn and Fe concentration (g/L and ppm, respectively). (b) $\mathrm{Zn}$ and Mn concentration (g/L). (c) $\mathrm{Zn}$ and Fe concentration ( $\mathrm{g} / \mathrm{L}$ and $\mathrm{ppm}$, respectively). 

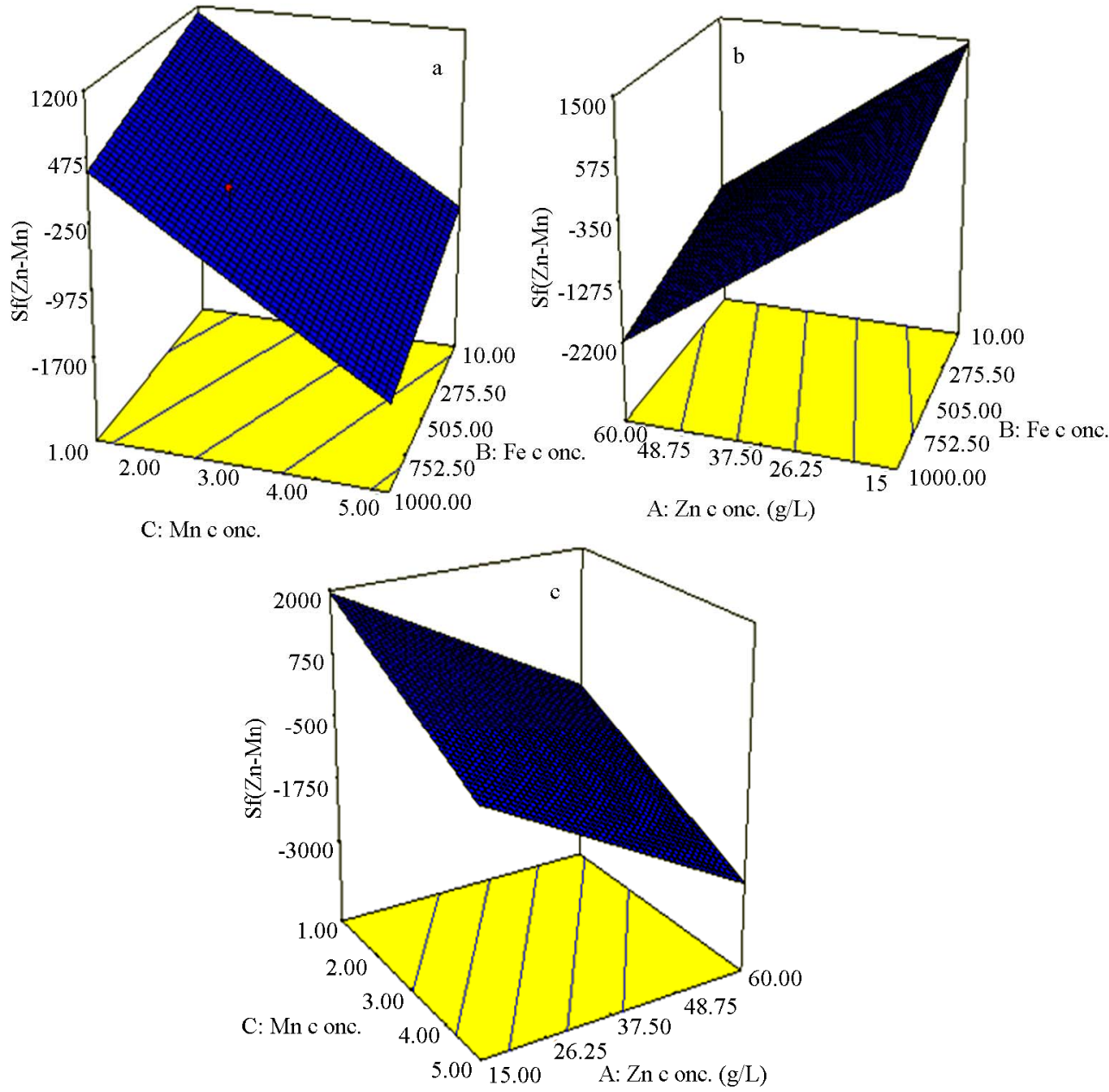

Figure 6. 3D response surface plots showing effect of two variables (factors) on separation factor of zinc-manganese at the center level of other variable. (a) $\mathrm{Mn}$ and Fe concentration (g/L and ppm, respectively). (b) $\mathrm{Zn}$ and Fe concentration (g/L and ppm, respectively) (c) Zn and Mn concentration (g/L).

Table 7. Results of process optimization and optimum levels of variable.

\begin{tabular}{|c|c|c|c|c|c|c|c|c|c|}
\hline Name & Goal & Zn (g/L) & $\mathrm{Fe}(\mathrm{ppm})$ & Mn (g/L) & $\% \mathrm{E} \mathrm{Zn}$ & $\% \mathrm{EFe}$ & $\% \mathrm{E} \mathrm{Mn}$ & Sf (Zn-Fe) & Sf (Zn-Mn) \\
\hline $\mathrm{Zn}$ & is in range & \multirow{8}{*}{21.22} & \multirow{8}{*}{376.08} & \multirow{8}{*}{1} & \multirow{8}{*}{93.72} & \multirow{8}{*}{99.20} & \multirow{8}{*}{11.18} & \multirow{8}{*}{8.10} & \multirow{8}{*}{1582.39} \\
\hline $\mathrm{Fe}$ & is in range & & & & & & & & \\
\hline Mn & is in range & & & & & & & & \\
\hline E Zn & maximize & & & & & & & & \\
\hline $\mathrm{EFe}$ & minimize & & & & & & & & \\
\hline E Mn & minimize & & & & & & & & \\
\hline $\mathrm{Sf}(\mathrm{Zn}-\mathrm{Fe})$ & maximize & & & & & & & & \\
\hline Sf (Zn-Mn) & maximize & & & & & & & & \\
\hline
\end{tabular}

optimum condition achieved 0.67 , which is statistically acceptable. Figure 7 shows the desirability of the optimum condition. As seen in this figure, at the optimum condition of iron concentration factor and the lowest levels of zinc and manganese concentration, the desirability of the model is high. 


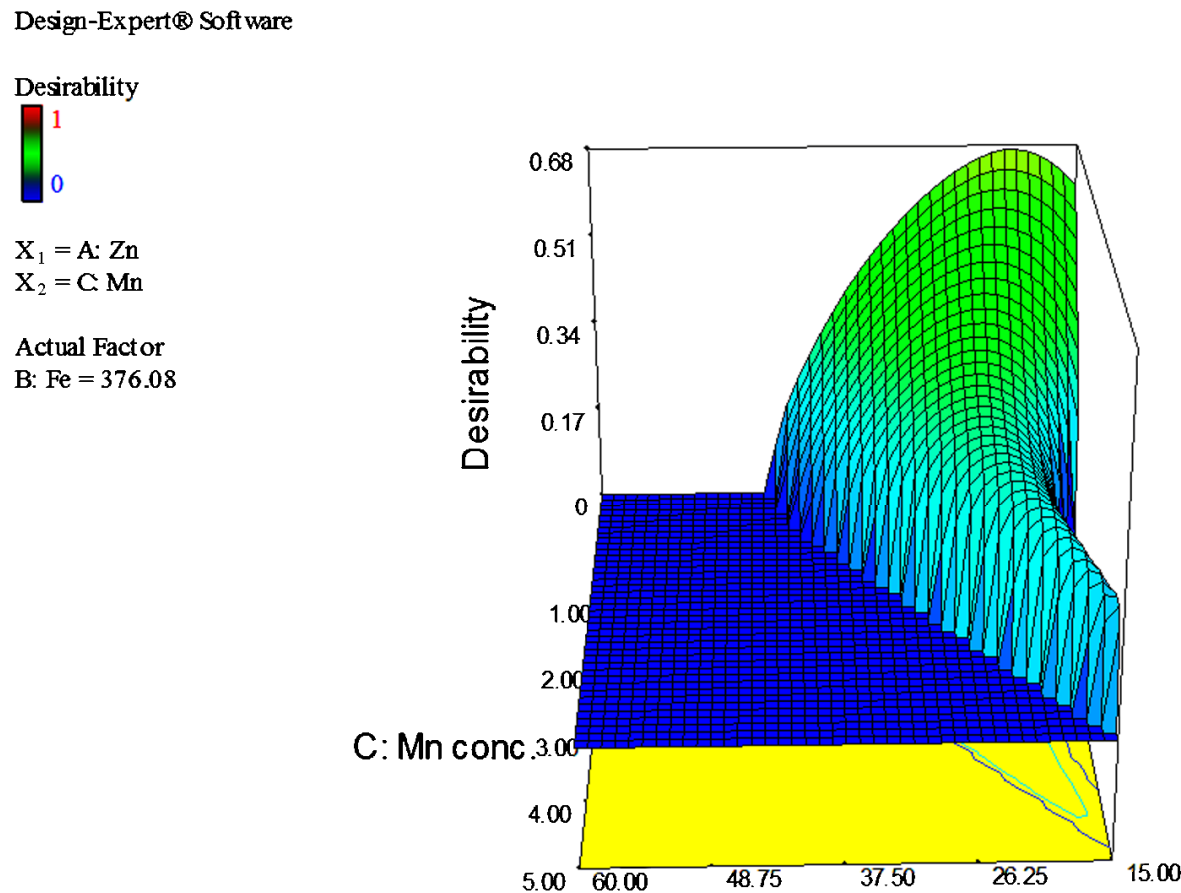

\section{A: Zn conc. (g/L) \\ Figure 7. Response surface plot showing effect of ions concentration on desirability of optimum condition.}

\section{Conclusions}

1) At the optimum condition, the zinc, iron and manganese extraction percent at $\mathrm{pH}$ of 2 and temperature of $40^{\circ} \mathrm{C}$ reached $93.72 \%, 99.20 \%$ and $11.18 \%$, respectively.

As a result, the best aqueous feed for extraction by $30 \%$

2) As ANOVA tables indicate, iron extraction and $\mathrm{Sf}(\mathrm{Zn}-\mathrm{Fe})$ are not significant responses to model.

3) Iron and manganese concentration had the highest effect on the zinc and manganese extraction, respectively.

\section{REFERENCES}

[1] E. Vahidi, F. Rashchi and D. Moradkhani, "Recovery of Zinc from an Industrial Zinc Leach Residue by Solvent Extraction Using D2EHPA,” Minerals Engineering, Vol. 22, No. 2, 2009, pp. 204-206. http://dx.doi.org/10.1016/j.mineng.2008.05.002

[2] M. Bolourfroush, M. Oliyazadeh and K. Gharibi, "Investigation of Zinv Solvent Extraction by D2EHPA,” Iranian Journal of Mining Engineering (IRJME), Vol. 2, No. 4, 2008, pp. 21-28.

[3] A. G. Pecherskaya and V. V. Stender, JPC, Vol. 9, No. 920, 1950.

[4] V. V. Stender and A. G. Pecherskaya, Non-Fer. Met, Vol. 45, No. 4, 1950.

[5] U. F. Turomoshina and V. V. Stender, JPC, Vol. 166, No.
2, 1955.

[6] P. Zaidler and V. V. Stender, JPC, Vol. 17, No. 282, 1944.

[7] I. Ivanov and Y. Stefanov, "Electroextraction of Zinc from Sulphate Electrolytes Containing Antimony Ions and Hydroxyethylated-butyne-2-diol-1,4: Part 3. The Influence of Manganese Ions and a Divided Cell," Hydrometallurgy, Vol. 64, No. 3, 2002, pp. 181-186. http://dx.doi.org/10.1016/S0304-386X(02)00039-7

[8] M. R. C. Ismael and J. M. R. Carvalho, "Iron Recovery from Sulphate Leach Liquors in Zinc Hydrometallurgy," Minerals Engineering, Vol. 16, No. 1, 2003, pp. 31-39. http://dx.doi.org/10.1016/S0304-386X(02)00039-7

[9] F. Principe and G. P. Demopoulos, "Comparative Study of Iron(III) Separation from Zinc Sulphate-Sulphuric Acid Solutions Using Organophosphorus Extractants, OPAP and D2EHPA: Part II. Stripping," Hydrometallurgy, Vol. 79, No. 3-4, 2005, pp. 97-109. http://dx.doi.org/10.1016/j.hydromet.2005.06.006

[10] Y. Sun, et al., "Optimizing the Extraction of Phenolic Antioxidants from Kudingcha made from Ilex Kudingcha C. J. Tseng by Using Response Surface Methodology," Separation and Purification Technology, Vol. 78, No. 3, 2011, pp. 311-320. http://dx.doi.org/10.1016/j.seppur.2011.01.038

[11] C.-H. Tan, et al., "Extraction and Physicochemical Properties of Low Free Fatty Acid Crude Palm Oil,” Food Chemistry, Vol. 113, No. 2, 2009, pp. 645-650. http://dx.doi.org/10.1016/j.foodchem.2008.07.052 